\title{
History, development and clinical perspectives of sutureless and rapid deployment surgical aortic valve replacement
}

\author{
Thierry Carrel, Paul Philipp Heinisch \\ Department for Cardiovascular Surgery, University Hospital and University of Bern, Bern, Switzerland \\ Correspondence to: Prof. Dr. Thierry Carrel. Clinic for Cardiovascular Surgery, University Hospital Bern, CH-3006 Bern, Switzerland. \\ Email: thierry.carrel@insel.ch.
}

\begin{abstract}
Degenerative aortic stenosis is the most frequent valvular heart disease in industrialized countries. Conservative treatment may beneficially influence symptoms but is never successful. Surgical aortic valve replacement (SAVR) was the only recognized treatment option to provide substantially prolonged survival until 2008. Operative mortality of isolated SAVR has been reported as low as $0.5 \%$ to $1 \%$ in experienced institutions, while long-term survival is close to that observed in a control healthy population of similar age. A multitude of studies have demonstrated the beneficial effects of SAVR with regard to improvement in quality of life and physical performance in the majority of symptomatic patients. In the last decade, transcatheter aortic valve implantation (TAVI) has emerged as an equal treatment modality, first in patients with high surgical risk and more recently in patients with intermediate and low surgical risk. Paravalvular regurgitation and the higher rate of pacemaker implantation remain points of consideration. Additionally, the long-term durability of TAVI devices and occurrence of stroke late after TAVI require additional analyses. Sutureless (SU-SAVR) and rapid deployment valve (R-SAVR) were designed to simplify and accelerate a conventional or less invasive surgical procedure while allowing complete excision of the calcified native valve. From 3 different implants tested more than 10 to 15 years ago, only two are available on the market today: the Perceval ${ }^{\circledR}$ valve from Liva Nova and the Intuity ${ }^{\circledR}$ sutureless prosthesis from Edwards Lifesciences. There has been extensive experience with these two devices in previous years and the results obtained are comparable to those observed following the use of conventional implants. The sutureless devices may be of particular interest for more complex and combined surgical procedures. This review summarizes the sutureless (SU-SAVR) and rapid deployment valve technologies and presents a clinical outlook for the patient population managed with these devices.
\end{abstract}

Keywords: Aortic valve stenosis; aortic valve regurgitation; surgical aortic valve replacement (SAVR); sutureless valves; rapid deployment valves

Submitted Feb 19, 2020. Accepted for publication May 07, 2020.

doi: 10.21037/acs-2020-surd-18

View this article at: http://dx.doi.org/10.21037/acs-2020-surd-18

\section{Treatment of valvular aortic stenosis}

Aortic stenosis is the most common heart valve disease in industrialized countries. The disease is caused by progressive calcification of the valve leaflets and not infrequently of the valvular annulus during a later phase. The degeneration leads to an increased pressure load on the left ventricle. If left untreated, aortic stenosis may have a similar prognosis to different types of cancer, with a life expectancy between 2 and 4 years, depending on the severity of the symptoms. Demographic studies have demonstrated that the prevalence of aortic valve stenosis is between $2-10 \%$ of the population aged older than $65(1,2)$. The second most frequent etiology is congenital stenosis, commonly associated with bicuspid anatomy, whilst rheumatic disease is still substantially causative in developing nations.

Echocardiography is the most important investigative tool used to confirm the diagnosis and the severity of aortic stenosis, once suspected by clinical examination and a 
precise description of the valve morphology is required. In addition, information on the size and the function of the left ventricle, the severity of hypertrophy (i.e., inclusively a localized, asymmetric septal hypertrophy that would require resection) and the size of the aortic root may be generated through transthoracic echocardiography. Current guidelines recommend aortic valve replacement as soon as the valve area is below $1.0 \mathrm{~cm}^{2}$ and the mean transvalvular pressure gradient is higher than $40-50 \mathrm{mmHg}$ (3). More recently, low-flow low-gradient aortic stenosis has been recognized as an established indication for replacement therapy as well. CT or magnetic resonance imaging allows a complete evaluation of the dimensions of the thoracic aorta (i.e., aortic root, ascending aorta and aortic arch), the diagnosis of calcifications (i.e., none, mild or porcelain aorta) as well as the precise anatomic location in the thorax to optimally prepare less invasive approaches and/ or to evaluate the suitability of a retrograde transaortic access for transcatheter aortic valve implantation (TAVI). Invasive transvalvular pressure recording and hemodynamic assessment, including pulmonary pressure, are performed during cardiac catheterization while coronary angiography is required in patients above 40 (men) or 50 (women) to exclude coronary artery disease.

The current indications for aortic valve replacement as well as the evidence for this therapeutic option have been summarized in the most recent Guidelines of the European Society of Cardiology-European Association of Cardiothoracic Surgery. All symptomatic patients with severe aortic stenosis should receive either SAVR or TAVI (3).

Surgical aortic valve replacement (SAVR) is one of the most frequent cardiac procedures and a definitive therapy that considerably improves symptoms and long-term survival; the procedure has been the gold standard for more than 50 years and the operative mortality has been described as low as $0.5 \%$ to $1 \%$ in experienced institutions, with promising long-term outcomes $(4,5)$. Other variables, such as age, gender, emergency operation, decreased leftventricular function, high blood pressure, coexisting coronary disease and reintervention procedures, may adversely influence the perioperative mortality. In these patients, TAVI has developed as an attractive alternative to SAVR in the last decade and will play an increasing role in the future. Sutureless rapid deployment valve prostheses are fabricated with a similar concept to TAVI but the role of these implants has still to be clarified.

Long-term survival after SAVR is comparable to that seen in a similar-age control population $(5,6)$. An improved subjective quality of life, a rise in physical performance and the significant increase in survival are classical benefits following surgery. If SAVR is needed, the selection of the optimal implant is crucial. Although mechanical valves are much longer lasting, a substantial proportion of the patients would prefer an option without life-long oral anticoagulation. This is exactly the major advantage of tissue valves, at the price of a "non-permanent" option, since tissue valves will degenerate after a certain period of time (i.e., depending on the age of the patient at implantation). Stentless and sutureless aortic valves were introduced with the hope of favourably influencing the rate of degeneration and/or to improving hemodynamic properties (e.g., lower transvalvular pressure gradients) compared to those of conventional valves.

Since 2008, TAVI has been demonstrated to be technically feasible and successful in a large proportion of patients, starting with older patients and with those presenting with a high surgical risk. Nowadays, TAVI is offered to the whole population that needs a tissue valve, meaning an increasingly younger and low-risk patient population (7-9). Even though the results have become similar to those obtained with SAVR, some concerns remain regarding the incidence and the severity of paravalvular regurgitation and the higher rate of pacemaker requirement. In addition, there are no comparable series of long-term results as there are for surgical tissue valves; therefore, the estimation of long-term durability remains scarce (10-14). Finally, some concerns have been raised regarding the longterm occurrence of stroke after TAVI.

Current guidelines are increasingly permissive for TAVI $(6,13)$. This means that results of SAVR must still be improved to keep competitive with those of TAVI. One way to fulfil this accomplishment may be obtained with the use of sutureless and rapid deployment valves. This might be of particular interest for specific conditions (e.g., less invasive solutions and complicated cases, such as mixed and therefore lengthy procedures) (15-17).

\section{The history of heart valve, with special reference to sutureless valves}

In 1954, Hufnagel and his collaborators identified 23 patients with a pure aortic regurgitation. At the time, the treatment offered consisted of expedient implantation of an acrylic ball valve into the descending aorta (18). As the valve blocked backward flow from the low part of the body only, the beneficial effect on heart function was limited. In 1961, Starr implanted the first mechanical heart valve-a caged ball 
designed valve-in a patient with mitral valve disease (19).

Researchers understood that an optimal cardiac valve device should be biocompatible, atraumatic for the blood flow and the blood cells and non-thrombogenic. Despite significant advances in technology, there are still no ideal valve replacement devices on the market. Both prosthetic implants (i.e., the mechanical and tissue valves) have certain benefits, but they also have numerous disadvantages. While mechanical valves provide long-term structural stability, they require long-term anticoagulation and the noise perceived by the patients may be disturbing $(20,21)$. In comparison, tissue valves mimic the normal blood flow through a native valve, are made of a biocompatible material (e.g., xeno-pericardial tissue) and do not require long-term anticoagulation. All these devices are subjected to microdestructive weakening of the valve over time (22).

Looking at the hemodynamics observed in conventional mechanical carbon valve devices, the non-physiologic closing of these bi-leaflet prostheses constitutes an imperative to look for a new tri-leaflet valve design (23). Advanced experimental, numerical and biomolecular blood flow analyses have shown that the reverse flow rather than the forward phase is responsible for platelet activation and micro-thrombus formation. These details have been widely overlooked and the surgical community still believes that cumadines are necessary following mechanical valve replacement because of the organic material that is exposed to the blood flow.

The actual interest is focused on the design of a new trileaflet valve that would be much more similar to that of a biological valve than a bi-leaflet valve in term of transvalvular blood flow. Such a valve combines the optimal hemodynamics of tissue valves with the durability of a mechanical one. In addition, computational modeling shows that this valve design closes much slower than a conventional bi-leaflet valve, quite similar to a tissue valve. Based on industrial design, the long-term durability of such a valve is quite predictable and that may challenge TAVI devices.

Between the classical surgical prostheses and the TAVI devices, sutureless and rapid deployment valves can be considered as a pertinent alternative that allows for quick placement into the aortic annulus via a surgical approach but without a sewing requirement $(15,16,24)$.

\section{Preliminary experience with sutureless valves, starting 2008}

Reports on experimental and clinical studies with sutureless valves have been already published in the early sixties, with the intention to promote easier implantation and shortening ischemic and perfusion times (25). This concept was ultimately not pursued because of various complications, including paravalvular leakage and thrombotic deposits on the device with subsequent peripheral embolization. Interestingly, the concepts for a sutureless device had a revival approximatively 20 years ago with the first prototypes being tested in animal experimentation. Parallel to these developments, the first concepts for transcatheter aortic valve technology were developed simultaneously. Both concepts were quite similar; one of the main characteristics of these new devices being the possibility to crimp them for the introduction into the definitive position.

Even though isolated SAVR is a technically simple procedure, there are considerable differences regarding the overall time needed for this intervention, including large differences in ischemic and perfusion times. One of the major features of sutureless valves was to make the procedure more reproducible, for instance, with less differences between very short and very long cross-clamp times, accelerating surgery but also allowing for a more stable fixation of the valve into the native anulus when a less invasive approach has been chosen and the accessibility for the classical fixation stitches may be compromised (26-28). In addition, one considerable advantage of sutureless valves is that, contrary to TAVI, the heavily calcified valve is completely excised; the latter condition may have at least a theoretically beneficial effect on the rate of subsequent prosthetic endocarditis. Three different sutureless prostheses received CE market approval: the $3 \mathrm{f}$ Enable ${ }^{\circledR}$ valve from ATS, later Medtronic, the Perceval $S^{\circledR}$ from Sorin, later Liva Nova and the Intuity ${ }^{\circledR}$ sutureless prosthesis from Edwards. Today, only the Perceval and the Intuity valves are still on the market, the 3-f Enable has been retired in 2014 most probably because of an increased risk of migration. At that time, the tool available for the loading and deployment of the Enable valve was rather uncomfortable. In the following, we will briefly present the 3 different devices that were developed for clinical use with a focus on the two that are still on the market today.

\section{The Enable valve from ATS-Medtronic}

The Enable valve concept originated from the combination of the $3 \mathrm{f}$ tubular stentless valve (Figure 1) with a nitinol stent that had the properties of being crimped without damage to the stent while the latter returned to its original 


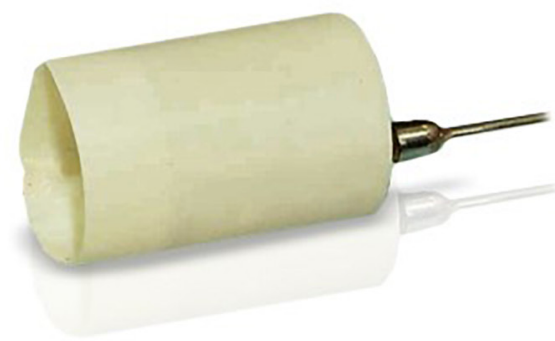

Figure 1 Tubular structure of the stentless 3-f aortic tissue valve.

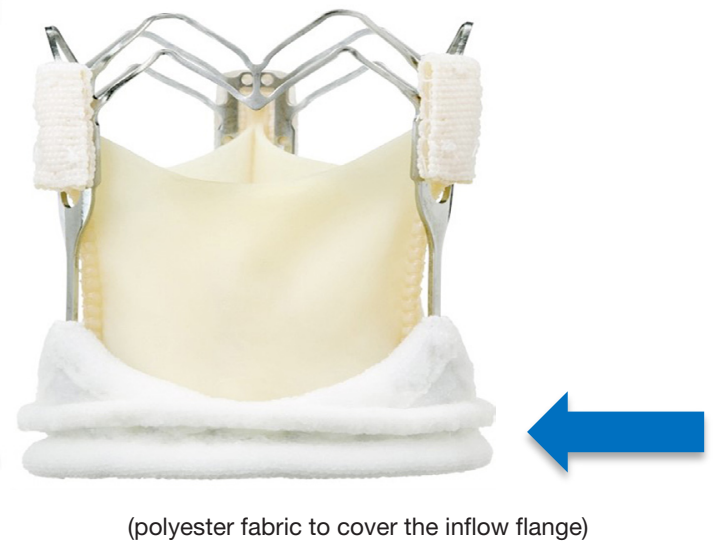

Figure 2 The sutureless $3 \mathrm{f}$ Enable ${ }^{\circledR}$ Aortic Bioprosthesis Model 6000 .

shape at normal temperature. The original stentless 3-f valve was designed to replicate the natural aortic valve's physiological function, according to the principle that form follows function (27).

The 3 -f valve was made of three similar segments of equine glutaraldehyde-fixed xeno-pericardial tissue. The cranial portion of the valve had three tabs reinforced through a small fabric piece each that had to be fixed to the aortic wall as neo-commissures to stabilize the leaflets. Systematic pre-clinical tests of $3 \mathrm{f}$ Aortic Bioprosthesis Model 1000 (the original stentless model) were carried out under the Food and Drug Administration (FDA) and the ISO Guidance. Together with widely deployed stentless and stented valves control measures, the in vitro and in
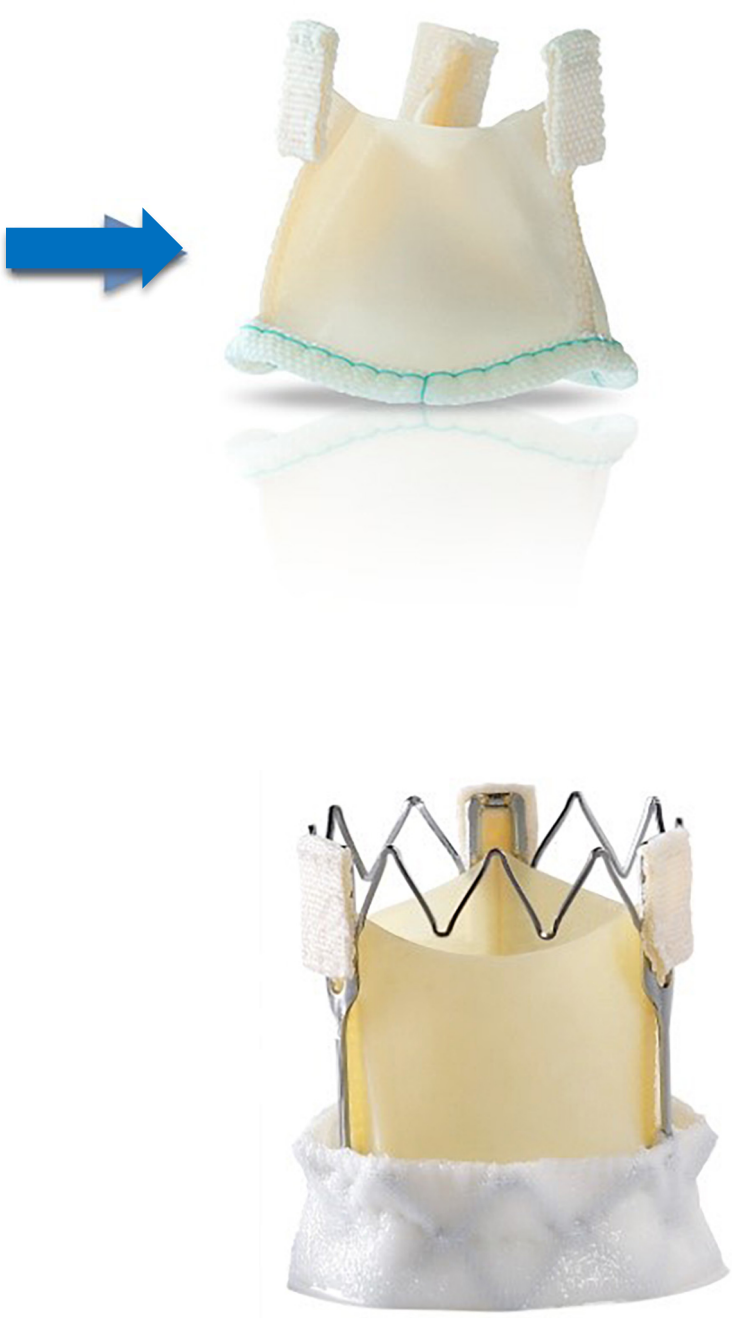

Figure 3 ATS $3 \mathrm{f}$ Enable $^{\circledR}$ Aortic Bioprosthesis Model 6000, Modified Frame.

vivo results were favourable. This valve was implanted in 165 patients as part of a worldwide, multicenter, nonrandomized study. During the entire study duration, there was no prosthetic degeneration nor valve thrombosis. After a five-year follow-up interval, the overall freedom from valve mortality was 98.5 percent (27).

\section{Enable I and II device description}

The $3 \mathrm{f}$ Enable ${ }^{\circledR}$ Aortic Bioprosthesis System 6000 was built from the stentless valve $3 \mathrm{f}$ and incorporated the tissue valve into a self-expanding Nitinol stent (Figure 2).

The Model 6000 design of the valve leaflets was identical to Model 1000 (Figure 3). The extended Nitinol structure 




Figure 4 Sutureless Perceval tissue valve.

contributed, thanks to externally induced radial factors embedded in the NiTiNOL component, to the stabilization of the unit in the angular position used. The polyester fabric surrounding the inflow contributed to a stable fixation at the level of the aortic annulus and the proximal portion of the aortic root. Similar to the development of TAVI devices, the polyester bridge of the Enable valve was added to the original design to mitigate perivalvular leakage and the danger of migration. The main difference between the initial and the updated versions were: size of the polyester fabric to increase the sealing properties within the aortic structures and the fact that the new frame was constructed to be crimped and not folded, allowing a circumferential deployment comparable to transcatheter valves.

Our institutional experience with this model was very favourable. We implanted this valve in 28 patients (mean age of $75.7 \pm 6.6$ years, Euro-Score of $7.1 \pm 1.7$ ). Due to cautious handling and the obligatory learning curve, the duration of cross-clamping and total perfusion times was not substantially shorter than those of isolated SAVR. The preliminary experience was satisfying without major perioperative complications (i.e., migration, obstruction of coronary ostia, interference with the mitral valve or traumatic injury of the ascending aorta) (28-30).

Transvalvular pressure gradients were comparable to those of stentless valves (mean $6.1 \pm 2.6 \mathrm{mmHg}$, peak $18 \pm 5 \mathrm{mmHg}$ ). Five patients $(18.5 \%)$ received permanent pacemaker implantation. Although the results were promising, Medtronic issued a field safety notice in November 2014 to alert physicians to the risk of migration with the $3 \mathrm{f}$ Enable Aortic Bioprosthesis (Model 6000) and to modify the instructions for use to recommend the use of two tied off guiding sutures. Since the issuance, the company did not receive any new reports of $3 \mathrm{f}$ Enable Aortic Bioprosthesis migration. While the revised instructions in the field safety notice continued to show positive outcomes, the product had seen limited commercial adoption. Therefore, Medtronic decided to discontinue the 3 f Enable Aortic Bioprosthesis (Model 6000) and the related accessories in May 2015 (31). We tried to find additional reasons for this. In fact, there were probably multiple: marginal teaching during the very initial experience, uncomfortable deployment using a cumbersome folding tool and finally the concurrential situation played by TAVI, that was in full development at that time.

\section{The Perceval S sutureless valve}

Perceval $\mathrm{S}$ is a sutureless aortic valve prosthesis made of bovine tissue pericardium attached to an automated anchor that is used to stabilize and fasten the implantation site (Figure 4). The configuration of the anchoring system consists of two segments (called the outflow and inflow rings), three valve-supporting elements and three sinusoidal elements that are positioned in the Valsalva sinuses (32).

The alloy used for the anchoring system is a Nickel/ Titanium equiatomic compound called Nitinol, capable of carrying large recoverable deformations (about 8-10 times the strength of the steel) and recovering its initial design when stress is removed (super elastic impact driven by deformation). The Perceval S prothesis can therefore be compressed for implantation and eventually reached its final diameter as soon as released.

The device is coated with a thin, turbostratic carbon film CarbofilmTM that improves haemo- and biocompatibility. The material is designed as every other pericardial valve: the scientifically validated valve configuration is equipped with a pericardial screw cap, which facilitates tolerance to the aortic annulus and avoids paravalvular leakage. A buttonhole placed at the level of the inflow assists the placement of the prothesis in relation to each valve sinus avoiding malrotation during inflation. A scientifically verified glutaraldehyde fixation cycle supported by the patented neutralization procedure for aldehyde compounds allows immediate implantation without rinsing, therefore making the time interval between unpacking and deployment very short. Perceval S foldable twin ended sizers aid the surgeon to select the best possible size of the prothesis: their construction allows identification of the annulus, even in complicated anatomy. Dedicated instruments assist 
A

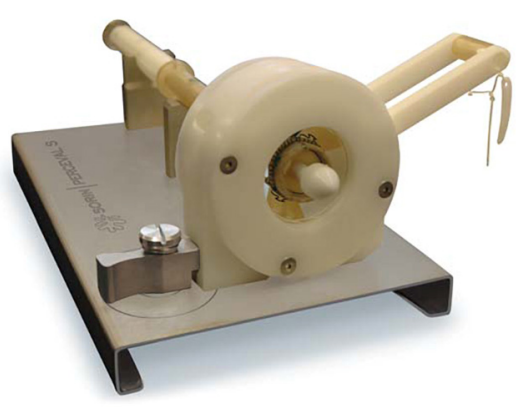

B

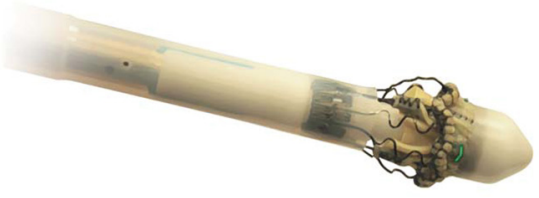

Figure 5 Valve to be crimped (A) and ready for implantation (B).

A

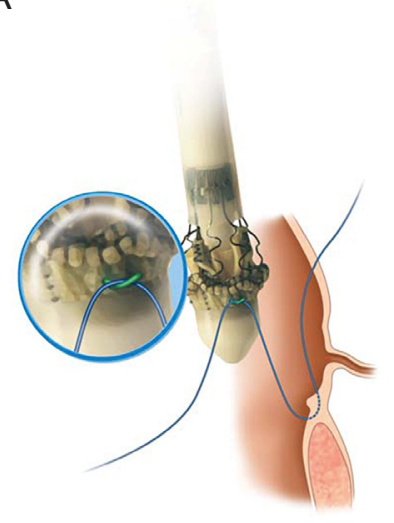

B

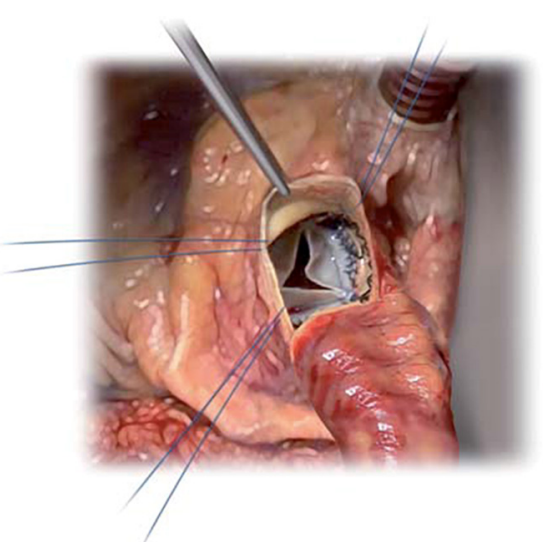

Figure 6 The guiding stitches are passed through the corresponding loops present at the external aspect of the inflow ring (A). The valve has been parachuted into position (B).



Figure 7 Final step of the implantation: dilatation of the Perceval $S$ valve into the aortic annulus. the implantation of the Perceval S valve: crimping device, manometer and expansion balloon (Figure 5). The size of the prosthesis is gradually reduced to a reasonable size before implantation with the Perceval S collapsing device and then placed onto the Perceval S frame (Figure 5). After introduction within the aortic anulus, the valve is opened in two phases: first the inflow ring is extracted at the level of the annulus and then the complete prosthesis release is performed when the surgeon can confirm the exact positioning (Figure 6). The post-dilatation ballon catheter is inserted into the prosthesis to optimize the position by forming the framework against the annulus at the inflow stage after insertion of the Perceval S (Figure 7).

The Perceval S prothesis was evaluated in three early phase clinical studies:

(I) The "PERCEVAL TRIAL-Perceval S valve pilot 


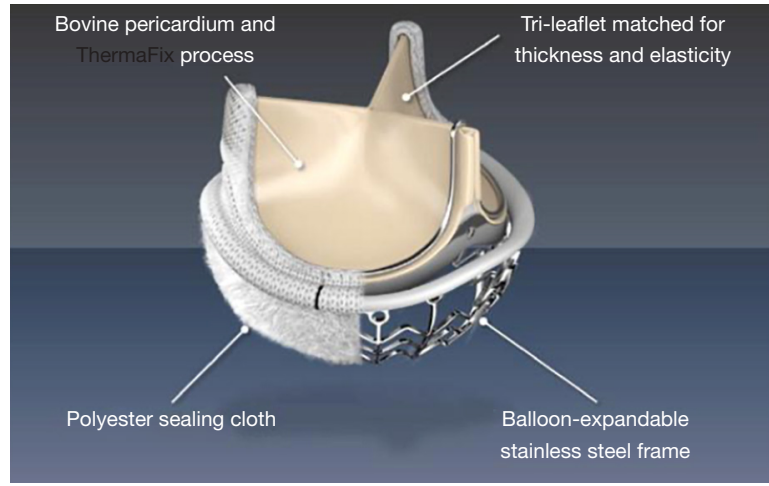

Figure 8 The intuity sutureless valve (courtesy from Edwards).

trial-V10601";

(II) The "PERCEVAL Pivotal Trial-V10801";

(III) The "CAVALIER-Perceval S valve clinical trial for extended CE mark-TPS001".

The first investigations were performed in 30 highrisk patients who were scheduled for isolated aortic valve replacement because of severe stenosis. This prospective analysis was undertaken at 3 European Centers from April 2007 to February 2008 (27) and concentrated on perioperative and one-year outcome. Patients enrolled for this study would be typical TAVI candidates in the classic setting. They had elevated risk for surgery (age 75 years and above, functional class NYHA III and IV, Logistic EuroSCORE $>5 \%$ ). Operative mortality was $3.3 \%, 1$ of 30 . During a mean follow-up of 12 months, there was no valve dislocation, but two patients had moderate paravalvular leaks (27-33).

According to the outcome of this pilot study, the Sorin Company planned the "PERCEVAL Pivotal StudyV10801" to support feasibility and efficiency in a larger cohort of patients. Between January 2009 and January 2010, 150 patients were studied in nine European institutions. The main goal was to assess the feasibility and the clinical performance of the Perceval S prothesis at 3-6 months. The main aspects of the analysis were the change in clinical status and the hemodynamic performance of the implant. In a third step, the CAVALIER trial intended to determine Perceval $S$ valve safety and efficiency in older patients ( $>65$ years) and with more valve sizes available $(21,23,25 \mathrm{~mm})$. The primary goal was to determine the safety and effectiveness of the Perceval S valve in the first 12 months. The research started in February 2010 with an overall number of patients exceeding 600 among 25 institutions (34). The 30-day results showed that the Perceval valve was safe (favourable haemodynamic effect and low complication rate), and may be recommended for SAVR since the technique is fast and reproducible after a short learning period.

In conclusion, the Perceval S sutureless bioprosthesis is easy-to-use and has a low-profile interface; the results seem to be reproducible as they were comparable among all centers included into the different trials. A special advantage of the device is that its deployment in a narrowed and/or calcified aortic root can be achieved quickly after a short learning curve. After adequate teaching, the Perceval $S$ Device may reduce the aortic cross-clamp time by approximatively 50 percent, with the shorter clamping time being about 15 to 18 minutes. A special indication could be the valve replacement in a degenerated homograft or in a degenerated porcine xenograft aortic root with circular wall calcification $(35,36)$. In this case, incision to enter into the aorta may be performed distally to the homograft. The length of the deployment device is long enough to reach the annulus of the homograft and safely fix the valve.

\section{The Intuity valve from Edwards Lifesciences}

This is the third sutureless valve device that was developed through Edwards Lifesciences. The valve system provides an innovative extended balloon structure for fast deployment. Anti-degeneration treatment includes the Thermafix method that is close to that used for the stented Perimount valve series by the same company. The Intuity ${ }^{\circledR}$ valve includes a widely spread polyester sealing cloth at the stage and just below the aortic valve anulus, covering the stainless-steel frame of the ballon (Figure 8). The specification includes Edwards Magna Ease technology (Edwards Lifesciences), which has proven sustained reliability and the SAPIEN transcatheter valve technology from Edwards $(37,38)$. The valve received CE market in February 2012.

Six European hospitals recruited 152 consecutive patients who required surgical aortic valve substitution in the prospective TRITON single-arm research study (37). The hemodynamic performance of this valve was very encouraging: average EOA and gradients at 3 months were $1.7 \pm 0.1 \mathrm{~cm}^{2}$ and $8.4 \pm 0.7 \mathrm{mmHg}$, with no changes at oneyear follow-up. Paravalvular leaks had a low incidence. The survival rate was at $98.6 \%$ at 30 days and $94 \%$ at one-year.

As for the Perceval S device, data on Intuity sutureless valves also revealed faster procedures characterized by shorter cross-clamp and cardiopulmonary bypass times. The aortic cross clamp times for simple aortic valve procedures 
decreased by $48 \%$ and average bypass times by $39 \%$ compared to times reported in the adult cardiac database of the Society of Thoracic Surgeons (37-39). Due to the excellent results obtained with the two devices still available on the market, a substantial number of surgeons now use one of these 2 devices for minimal-invasive approaches (upper sternotomy and lateral thoracotomy).

\section{Current clinical perspective}

In the current era, cardiac surgeons are challenged through the rapid growth of transcatheter aortic valve implantation (TAVI) cases. To ensure the continued existence of the golden standard of SAVR, at least for those for whom a TAVI is not indicated, the outcomes still may be further improved. One of the main objectives is to mitigate surgical damage and establish new concepts for valve devices and new methods for surgical valve replacement. To define the benefit of sutureless and rapid deployment valves in current minimally invasive approaches in isolated aortic valve replacement, a panel of 28 international experts with expertise in both minimally invasive aortic valve replacement and rapid deployment valves was constituted. After thorough literature review, the experts rated evidencebased recommendations but no guidelines could be established (40).

Different studies have been performed on sutureless aortic valves (SU-SAVR) or rapid deployment of aortic valves (R-SAVR) (41-45). In terms of clinical and hemodynamic behaviour, both valves seem very comparable and appropriate for the majority of procedures. Certain circumstances contribute to the choice of one over the other. In particular, when SAVR is planned through a less invasive approach, the Perceval-S valve may be a safer choice, since it folds on the holder systems and the view of the aortic annulus is optimized during implantation; however, the implantation of the Perceval-S requires a more cranial horizontal aortotomy that makes a concomitant replacement of the ascending aorta more complex. After implantation of the Intuity valve, transvalvular gradients are the lowest. All studies confirm the two major advantages: reducing surgical times and simplifying minimally invasive methods. The careful differentiation between R-SAVR and SU-SAVR is needed in clinical practice for the assessment of the outcomes, since both valve types vary significantly in structure and technique of implants.

While both valves are scientifically and hemodynamically comparable and are ideal replacement devices for the majority of patients, there are few conditions where one device may be better appropriated than the other. In fact, the Perceval-S valve can be more suited during less invasive SAVR through right anterior thoracotomy, because it is collapsible in the holder, thus giving maximal visibility to optimally position and deploy the device into the aortic annulus. Nonetheless, Perceval-S implant requires a more cranial transverse aortotomy which makes radical supracoronary repair of the ascending aorta more difficult.

The average rates of postoperative pacemaker implantation (PPI) following TAVI have been around approximately $15-25 \%$, with significant difference according to the type of TAVI device (46-49). Early PPI estimates were found to be as low as 3.0 percent following conventional sutured SAVR (50). The SU-SAVR and R-SAVR anchoring systems are comparable to transcatheter devices; as a consequence, patients are at increased risk of atrioventricular block postoperatively (51). The SU-SAVR nitinol stent and the expandable R-SAVR skirt contribute to higher tension in the left ventricular outflow tract and thus ultimately to atrioventricular conduction tissue. PPI is at $4.6 \%$ in the SU-SAVR group and $6.2 \%$ in the R-SAVR group with no clinically relevant difference (15). The rate of permanent pacemaker is considerably higher than those observed following standard SAVR prosthesis.

A new meta-analysis found an increased rate of PPI in patients with SU-SAVR valves (7.9\%) compared to traditional SAVR implants (3.1\%) (46). The differences reported in the rates of PPIs need to be carefully interpreted: the devices demonstrate large variations on the depth of the valve into the outflow tract. In addition, the sizing of the valve often becomes crucial, and "learning" surgeons tend to over-size the valve to prevent leakages, which can lead to higher radial pressure across the subvalvular rim. Regarding the hemodynamic benefits, results reported in the literature are somewhat controversial. The R-SAVR displayed lower average peak and mean gradients, this has been confirmed by a direct comparison with SU-SAVR (15). Absolute figures indicate only a small gap between the two systems. A newer study comprising INTU-ITA data alone indicates that peak and average gradients remain constant until four years after implantation (42).

\section{Outlook and take-home message}

In this short overview, we have tried to summarize the historical evolution of the introduction of sutureless valves alongside the introduction of TAVI. The following 
chapters will present in depth clinical experience with larger cooperative studies between expert institutions. There has been several platforms reporting the results of sutureless valve devices. A comprehensive clinical data report on safety, effectiveness and hemodynamic efficiency was developed in 2014 under the auspices of the International Valvular Surgery Study Group. It consisted of 36 cardiac surgeons from 27 major centers worldwide. The projects included historical as well as potential trials of the International SUAVR registry which have been reported in recent years (40,52).

The subsequent technical advances in aortic valve replacement (SAVR) with R-SAVR and SU-SAVR push the surgeons to further ameliorate their own results: shorter crossclamp and $\mathrm{CPB}$ times and an increase in the rate of minimal invasive procedures. Both systems demonstrated comparable, promising results in terms of hemodynamic efficiency, reliability and safety. The implantation technique requires specialized instruction for the first 5 to 10 cases while in some institutions the incidence of PPI remains a concern. SU-SAVR and R-SAVR have helped to further improve the results of SAVR in different subsets of patients $(53,54)$; this procedure is competitive with TAVI. The diversity of the observed benefits is underreported and thus it will be important to confirm beneficial results by longterm examinations of detailed data collection.

\section{Acknowledgments}

None.

\section{Footnote}

Conflicts of Interest: Both authors have completed the ICMJE uniform disclosure form (available at http://dx.doi. org/10.21037/acs-2020-surd-18). TC received speaker fees and funding for research for ATS Medical and Medtronic (2008-2014) and speaker fees from Sorin Medical and Edwards Lifesciences. The other author has no conflicts of interest to declare.

Open Access Statement: This is an Open Access article distributed in accordance with the Creative Commons Attribution-NonCommercial-NoDerivs 4.0 International License (CC BY-NC-ND 4.0), which permits the noncommercial replication and distribution of the article with the strict proviso that no changes or edits are made and the original work is properly cited (including links to both the formal publication through the relevant DOI and the license). See: https://creativecommons.org/licenses/by-nc-nd/4.0/.

\section{References}

1. Iung B, Baron G, Butchart EG, et al. A prospective survey of patients with valvular heart disease in Europe: The Euro Heart Survey on Valvular Heart Disease. Eur Heart J 2003;24:1231-43.

2. Otto CM, Lind BK, Kitzman DW, et al. Association of aortic valve sclerosis with cardiovascular mortality and morbidity in the elderly. N Engl J Med 1999;341:142-7.

3. Falk V, Baumgartner H, Bax JJ, et al. 2017 ESC/EACTS Guidelines for the management of valvular heart disease. Eur J Cardiothorac Surg 2017;52:616-64.

4. Kvidal P, Bergström R, Hörte LG, Observed and relative survival after aortic valve replacement. J Am Coll Cardiol 2000;35:747-56.

5. Rodriguez-Gabella T, Voisine P, Dagenais F, et al. LongTerm Outcomes Following Surgical Aortic Bioprosthesis Implantation. J Am Coll Cardiol 2018;71:1401.

6. Chiang YP, Chikwe J, Moskowitz AJ, et al. Survival and long-term outcomes following bioprosthetic vs mechanical aortic valve replacement in patients aged 50 to 69 years. JAMA 2014;312:1323-9.

7. Chakos A, Wilson-Smith A, Arora S, et al. Long term outcomes of transcatheter aortic valve implantation (TAVI): a systematic review of 5 -year survival and beyond. Ann Cardiothorac Surg 2017;6:432-43.

8. Waksman R, Rogers T, Torguson R, et al. Transcatheter Aortic Valve Replacement in Low-Risk Patients With Symptomatic Severe Aortic Stenosis. J Am Coll Cardiol 2018;72:2095-105.

9. Kolkailah AA, Doukky R, Pelletier MP, et al. Transcatheter aortic valve implantation versus surgical aortic valve replacement for severe aortic stenosis in people with low surgical risk. Cochrane Database Syst Rev 2019;12:CD013319.

10. Søndergaard L, Ihlemann N, Capodanno D, et al. Durability of Transcatheter and Surgical Bioprosthetic Aortic Valves in Patients at Lower Surgical Risk. J Am Coll Cardiol 2019;73:546-53.

11. Murray MI, Hofmann E, De Rosa R, et al. Hemodynamic Outcome and Valve Durability Beyond Five Years After Transcatheter Aortic Valve Replacement. J Invasive Cardiol 2020;32:82-7.

12. Shah $\mathrm{K}$, Chaker Z, Busu T, et al. Meta-Analysis comparing the frequency of stroke after transcatheter versus surgical 
aortic valve replacement. Am J Cardiol 2018;122:1215-21.

13. Jakobsen L, Terkelsen CJ, Sondergaard L, et al. Shortand long-term mortality and stroke risk after transcatheter aortic valve implantation. Am J Cardiol 2018;121:78-85.

14. Muntané-Carol G, Urena M, Munoz-Garcia A, et al. Late Cerebrovascular Events Following Transcatheter Aortic Valve Replacement. JACC Cardiovasc Interv 2020;13:872-81.

15. D'Onofrio A, Salizzoni S, Filippini C, et al. Surgical aortic valve replacement with new-generation bioprostheses: Sutureless versus rapid-deployment. J Thorac Cardiovasc Surg 2019;159:432-42.

16. Andreas M, Coti I, Rosenhek R, et al. Intermediateterm outcome of 500 consecutive rapid-deployment surgical aortic valve procedures. Eur J Cardiothorac Surg 2019;55:527-33.

17. Laufer G, Wiedemann D, Chitwood WR. Rapiddeployment valves: Finally the fog is lifting-benefits beyond crossclamp and bypass times. J Thorac Cardiovasc Surg 2017;154:1527-31.

18. Hufnagel CA, Harwey WP, Rabil PJ, et al. Surgical correction of aortic insufficiency. Surgery 1954;35:673-83.

19. Starr A, Edwards ML. Mitral replacement: clinical experience with a ball-valve prosthesis. Ann Surg 1961;154:726-40.

20. Chaikof EL. The development of prosthetic heart valves - lessons in form and function. $\mathrm{N}$ Engl J Med 2007;357:1368-71.

21. Grunkemeier GL, Li HH, Naftel DC, et al. Long-term performance of heart valve prostheses. Curr Probl Cardiol 2000;25:73-154.

22. Baldwin ACW, Tolis G. Tissue valve degeneration and mechanical valve failure. Curr Treat Options Cardiovasc Med 2019;21:33.

23. Carrel T, Dembitsky WP, de Mol B, et al. Non-physiologic closing of bi-leaflet mechanical heart prostheses requires a new tri-leaflet valve design. Int J Cardiol 2020 304:125-7.

24. Di Eusanio M, Phan K, Berretta P, et al. Sutureless and Rapid-Deployment Aortic Valve Replacement International Registry (SURD-IR): early results from 3343 patients. Eur J Cardiothorac Surg 2018;54:768-73.

25. Magovern GJ, Cromie HW. Sutureless prosthetic heart valves. J Thorac Cardiovasc Surg 1963;46:726-36.

26. Wendt D, Thielmann M, Buck T, et al. First clinical experience and 1-year follow-up with the sutureless 3F-Enable aortic valve prosthesis. Eur J Cardiothorac Surg 2008;33:542-7.

27. Pillai R, Ratnatunga C, Soon JL, et al. $3 f$ prosthesis aortic cusp replacement: implantation technique and early results. Asian Cardiovasc Thorac Ann 2010;18:13-6.

28. Aymard T, Kadner A, Walpoth N, et al. Clinical experience with the second-generation $3 \mathrm{f}$ Enable sutureless aortic valve prosthesis. J Thorac Cardiovasc Surg 2010;140:313-6.

29. Englberger L, Carrel TP, Doss M, et al. Clinical performance of a sutureless aortic bioprosthesis: Fiveyear results of the $3 \mathrm{f}$ Enable long term follow-up study. J Thorac Cardiovasc Surg 2014;148:1681-7.

30. Martens S, Sadowski J, Eckstein FS, et al. Clinical experience with the ATS $3 \mathrm{f}$ Enable ${ }^{\circledR}$ Sutureless Bioprosthesis. Eur J Cardiothorac Surg 2011;40:749-55.

31. Medtronic. Personal written communication, May 2015.

32. Shrestha M, Fischlein T, Meuris B, et al. European multicentre experience with the sutureless Perceval valve: clinical and haemodynamic outcomes up to 5 years in over 700 patients. Eur J Cardiothorac Surg 2016;49:234-41.

33. Shrestha M, Khaladj N, Bara C, et al. A staged approach towards interventional aortic valve implantation with a sutureless valve: initial human implants. Thorac Cardiovasc Surg 2008;56:398-400.

34. Laborde F, Fischlein T, Hakim-Meibodi K, et al. Clinical and haemodynamic outcomes in 658 patients receiving the Perceval sutureless aortic valve: early results from a prospective European multicentre study (the Cavalier Trial). Eur J Cardiothorac Surg 2016;49:978-86.

35. Folliguet TA, Laborde F. Sutureless Perceval aortic valve replacement in aortic homograft. Ann Thorac Surg 2013;96:1866-8.

36. Villa E, Messina A, Cirillo M, et al. Perceval sutureless valve in freestyle root: new surgical valve-in-valve therapy. Ann Thorac Surg 2013;96:e155-7.

37. Kocher AA, Laufer G, Haverich A, et al. One-year outcomes of the Surgical Treatment of Aortic Stenosis With a Next Generation Surgical Aortic Valve (TRITON) trial: a prospective multicenter study of rapid-deployment aortic valve replacement with the EDWARDS INTUITY Valve System. J Thorac Cardiovasc Surg 2013;145:110-5; discussion 115-6.

38. Brennan JM, Holmes DR, Sherwood MW, et al. The association of transcatheter aortic valve replacement availability and hospital aortic valve replacement volume and mortality in the United States. Ann Thorac Surg 2014;98:2016-22.

39. Goel S, Pasam RT, Wats K, et al. Transcatheter aortic valve replacement versus surgical aortic valve replacement in low-surgical-risk patients: An updated meta-analysis. 
Catheter Cardiovasc Interv 2020;96:169-78.

40. Glauber M, Moten SC, Quaini E, et al. International Expert Consensus on Sutureless and Rapid Deployment Valves in Aortic Valve Replacement Using Minimally Invasive Approaches. Innovations (Phila) 2016;11:165-73.

41. Berastegui García E, Camara Rosell ML, Estevez Cid F, et al. Perceval Less Invasive Aortic Replacement Register: multicentric Spanish experience with the Perceval S bioprosthesis in moderate-high-risk aortic surgery. Interact Cardiovasc Thorac Surg 2018;26:596-601.

42. D'Onofrio A, Tarja E, Besola L, et al. Early and Midterm Clinical and Hemodynamic Outcomes of Transcatheter Valve-in-Valve Implantation: Results From a Multicenter Experience. Ann Thorac Surg 2016;102:1966-73.

43. D'Onofrio A, Tessari C, Filippini C, et al. Early and Mid-Term Results of Rapid Deployment Valves: The Intuity Italian Registry (INTU-ITA). Ann Thorac Surg 2018;106:1742-9.

44. Meco M, Montisci A, Miceli A, et al. Sutureless Perceval Aortic Valve Versus Conventional Stented Bioprostheses: Meta-Analysis of Postoperative and Midterm Results in Isolated Aortic Valve Replacement. J Am Heart Assoc 2018;7:701.

45. Borger MA, Moustafine V, Conradi L, et al. A randomized multicenter trial of minimally invasive rapid deployment versus conventional full sternotomy aortic valve replacement. Ann Thorac Surg 2015;99:17-25.

46. Jarrett CM. Permanent pacemaker insertion following transcatheter aortic valve replacement: Not infrequent, not benign, and becoming predictable. J Thorac Cardiovasc Surg 2017;153:1063-4.

47. Gaede L, Kim WK, Liebetrau C, et al. Pacemaker

Cite this article as: Carrel T, Heinisch PP. History, development and clinical perspectives of sutureless and rapid deployment surgical aortic valve replacement. Ann Cardiothorac Surg 2020;9(5):375-385. doi: 10.21037/acs-2020surd-18 implantation after TAVI: predictors of AV block persistence. Clin Res Cardiol 2018;107:60-9.

48. Arnold SV, Manandhar P, Vemulapalli S, et al. Impact of Short-Term Complications of TAVR on Longer-Term Outcomes: Results from the STS/ACC Transcatheter Valve Therapy Registry. Eur Heart J Qual Care Clin Outcomes 2020. [Epub ahead of print].

49. Faroux L, Chen S, Muntané-Carol G, et al. Clinical impact of conduction disturbances in transcatheter aortic valve replacement recipients: a systematic review and meta-analysis. Eur Heart J 2020;41:2771-81.

50. Matthews IG, Fazal IA, Bates MGD, et al. In patients undergoing aortic valve replacement, what factors predict the requirement for permanent pacemaker implantation? Interact Cardiovasc Thorac Surg 2011;12:475-9.

51. Vogt F, Pfeiffer S, Dell'Aquila AM, et al. Sutureless aortic valve replacement with Perceval bioprosthesis: are there predicting factors for postoperative pacemaker implantation? Interact Cardiovasc Thorac Surg 2016;22:253-8.

52. Gersak B, Fischlein T, Folliguet TA, et al. Sutureless, rapid deployment valves and stented bioprosthesis in aortic valve replacement: Recommendations of an International Expert Consensus Panel. Eur J Cardiothorac Surg 2016;49:709-18.

53. Accola KD, Chitwood WR, Mumtaz MA, et al. Stepby-Step Aortic Valve Replacement With a New Rapid Deployment Valve. Ann Thorac Surg 2018;105:966-71.

54. Borger MA, Dohmen P, Misfeld M, et al. Current trends in aortic valve replacement: development of the rapid deployment EDWARDS INTUITY valve system. Expert Review of Medical Devices 2013;10:461-70. 